\title{
Performance Analysis of Energy Aware AODV Routing Protocol for IEEE 802.15.4 Enabled WSN
}

\author{
P.Samundiswary and Hemant Bhardwaj \\ Dept. of Electronics Engineering \\ Pondicherry University, Pondicherry, INDIA
}

\begin{abstract}
In the present scenario, wireless network is being widely used in the area where infrastructure based telecommunication system are unavailable. The mobile adhoc network is the infrastructure-less mobile network which has no fixed infrastructure and the nodes can be connected dynamically in an arbitrary manner. The sensor networks are incarnated from ad-hoc networks in which nodes have sensing capability. There are several communication protocols available for wireless sensor networks such as Ad hoc On demand Distance Vector (AODV), Dynamic Source Routing (DSR), Dynamic Destination Sequenced Distance Vector (DSDV). AODV is an on demand dynamic routing protocol that uses sequence number to determine the timeliness of each packet and to prevent loops. The main advantage of this protocol is to establish routes on demand and destination sequence numbers are available for finding the latest route to the destination. However, nodes in sensor networks are usually powered by batteries, which provide a limited amount of energy since sensor nodes have limited battery power. Hence it is required to develop energy efficient routing protocols to optimize the performance of the network. In this paper, Energy Aware AODV (EAODV) routing protocol for IEEE 802.15.4 enabled WSN is developed to improve the performance of the network. The energy aware AODV protocol for IEEE 802.15.4 enabled WSN is done by incorporating the residual energy in the RREQ message of the existing AODV protocol. Further, the performance metrics such as delivery ratio and delay are determined and analyzed for various simulation times and coverage area.
\end{abstract}

Keywords

WSN, DSR, AODV, RREQ, RREP, EAODV

\section{INTRODUCTION}

Wireless Sensor Networks [1] are a new class of ad hoc networks that will find increasing deployment in recent years. Sensor networks enable reliable monitoring and analysis of the unknown and untested environment. Ease of deployment, extended range, fault-tolerance and mobility are some of the advantages of wireless sensor networks. Wireless sensor nodes are expected to be extremely small and battery operated. Protocols for these networks must be designed in such a way that the limited power in the sensor nodes should be used in the most efficient manner. Currently available sensors are made large (and expensive) to cover as much area as possible [2]. Each of these has a constant power supply and communicates their data to the end-user using a wired network. The organization of such a network has to be preplanned to find strategic positions to place these nodes and then has to be installed appropriately. The failure of a single node might bring down the whole network or leave that region completely uncovered. Recently, many researchers have shown great interest in developing energy efficient routing protocols [3], [4] which use the limited energy of sensors thus leads to the improvement in the lifetime of the network. Hence, an attempt has been made to implement energy aware ad hoc on demand distance vector routing protocol for IEEE 802.15.4 enabled WSN by appending the residual energy in the frame format of existing AODV protocol which is discussed in this paper. This energy aware ad hoc on demand routing protocol for IEEE 802.15.4 enabled WSN is simulated by using ns-2.35 for different coverage areas and simulation time with 100 nodes in the network. The paper is organized as follows: Section 2 explains about the ad-hoc on demand distance vector routing. Section 3 describes about the proposed energy aware ad-hoc on demand distance vector routing for IEEE 802.15 enabled wireless sensor network. Simulation results are discussed in Section 4 and conclusions are drawn in Section5

\section{AD HOC ON DEMAND DISTANCE VECTOR ROUTING PROTOCOL}

AODV is a reactive protocol that determines routes ondemand [5]. It is based on the distance vector technology. When a source host wants to send packets to the destination and cannot get the routes from its routing table, it will broadcast a Route Request (RREQ). The receivers may establish the routes back to the source host through the paths that they get the RREQ [6]. If the receiver has an active route to the destination, it will be unicast a Route Reply (RREP) back to the source. Otherwise, the RREQ will be re-broadcast further. If a reply is sent, all hosts along that path may record the route to the destination through this packet. Because there may exist multiple exclusive paths between two hosts, a mobile host can receive the same RREQ more than once. To prevent the same request from being broadcast repeatedly, every request is uniquely identified by a Host ID, Broadcast ID couple [7]. Every host keeps a record for the RREQs that have been processed. The mobile hosts send out the Route Error (RERR) packets to their neighbors to report broken paths and activate the route re-discovery procedure.

To avoid routing loop and identify the freshness of the route, destination sequence number is introduced. The sequence number [8] of a mobile host can only be updated by itself in monotonically increasing mode. A larger sequence number denotes a fresher route. The sequence number is carried in both RREQ and RREP. The sequence number in RREP must be larger than or equal to the one carried in corresponding RREQ to avoid the source host to adopt a stale path. When more than one path represented by different RREPs is available, the one with the largest destination sequence number is used. If several paths have 
the same sequence number, the shortest one is chosen [9]. AODV's desirable features are its low byte overhead in relatively static networks and loop free routing using the destination sequence numbers. However, the lifetime of network is reduced by using the same nodes (having shortest route) repeatedly for transferring the data from source to destination nodes.

\section{ENERGY AWARE AD HOC ON DEMAND DISTANCE VECTOR ROUTING PROTOCOL}

The proposed protocol performs a route discovery process similar to the AODV protocol [10]. The difference is to determine an optimum route by considering the network lifetime performance; that is, considering residual energy of nodes on the path and hop count. To identify each node distinctly, a unique node identification number (node id) is used. Each message field of EAODV for IEEE 802.15.4[11] enabled WSN contains the following blocks as shown in Figure 1.

Figure 1. Frame format of Message field of EAODV

Previous Pointer: The pointer points to the previous node in the route from source to Destination. Previous pointer at a source node where the message has generated holds a null value.

Next pointer: It points to the next node in the route from source to destination.

Sequence no: It gives a unique sequence number to messages for a particular job Requirement template.

Hop Counter: It counts the number of traveled nodes.

Job Requirement Template: This template contains the minimum part of the job Requirement template which is required to be matched

In order to implement residual energy in EAODV protocol, a new field, called Min-RE (Minimum Residual Energy) field, is added to the RREQ message as shown in Figure 2. The Min-RE field is set as a default value of -1 when a source node broadcasts a new RREQ message for a route discovery process.

\begin{tabular}{|c|}
\hline RREQ ID \\
\hline DESTINATION IP ADDRESS \\
\hline DESTINATION SEQUENCE NUMBER \\
\hline ORIGINATOR IP ADDRESS \\
\hline ORIGINATOR SEQUENCE NUMBER \\
\hline MINIMAL RESIDUAL ENERGY (ADDED) \\
\hline
\end{tabular}

\section{Figure 2. A RREQ message format for EAODV}

To find a route to a destination node, a source node floods a RREQ packet to the network. When neighbor nodes receive the RREQ packet, they update the Min-RE value and rebroadcast the packet to the next nodes until the packet arrives at a destination node. If the intermediate node receives a RREQ message, it increases the hop count by one and replaces the value of the Min-RE field with the minimum energy value of the route. In other words, Min$\mathrm{RE}$ is the energy value of the node if Min-RE is greater than its own energy value; otherwise Min-RE is unchanged. Although intermediate nodes have route information to the destination node, they keep forwarding the RREQ message to the destination because it has no information about residual energy of the other nodes on the route. If the destination node finally receives the first RREQ message, it triggers the data collection timer and receives all RREQ messages forwarded through other routes until time expires. After the destination node completes route information collection, it determines an optimum route and then sends a RREP message to the source node by unicasting. If the source node receives the RREP message, a route is established and data transfer gets started. Such route processes are performed periodically, though node topology does not change to maintain node energy consumption balanced. That is, the periodic route discovery will exclude the nodes having low residual energy from the routing path and greatly reduce network partition.

\begin{tabular}{|l|l|l|l|l|}
\hline $\begin{array}{l}\text { Previous } \\
\text { pointer }\end{array}$ & $\begin{array}{l}\text { Next } \\
\text { pointer }\end{array}$ & $\begin{array}{l}\text { Sequence } \\
\text { no }\end{array}$ & $\begin{array}{l}\text { Hop } \\
\text { counter }\end{array}$ & $\begin{array}{l}\text { Job } \\
\text { requirement } \\
\text { template }\end{array}$ \\
\hline
\end{tabular}

\section{RESULTS AND DISCUSSION}

AODV and EAODV protocol are simulated by using network simulator (ns-2) [12] of version 2.35 , by varying the coverage area from $50 \times 50\left(\mathrm{~m}^{2}\right)$ to $200 \times 200\left(\mathrm{~m}^{2}\right)$ and simulation time from $100 \mathrm{~s}$ to $400 \mathrm{~s}$. Then the performance parameters such as delivery ratio and delay are determined and analyzed for AODV and EAODV protocol by varying simulation time and coverage area. The simulation parameters used for simulation is given in table 1 .

Table 1. Simulation Parameters

\begin{tabular}{|l|l|}
\hline Simulation Parameters & Values \\
\hline IEEE Standard & 802.15 .4 \\
\hline Traffic mode & CBR \\
\hline Simulation time & $100(\mathrm{~s})$ to $400(\mathrm{~s})$ \\
\hline No of mobile nodes & 100 \\
\hline Routing protocol & $\mathrm{AODV}$ \\
\hline Area $\left(\mathrm{m}^{2}\right)$ & $50 \times 50\left(\mathrm{~m}^{2}\right)$ to $200 \times 200\left(\mathrm{~m}^{2}\right)$ \\
\hline Simulation platform & $\mathrm{NS}-2.35$ \\
\hline
\end{tabular}

\subsection{Delivery Ratio Analysis}

EAODV outperforms AODV by achieving higher delivery ratio for different simulation times with 100 nodes as illustrated by the Figure3. As the simulation time increases the delivery ratio decreases because the packet loss will be increased due to the increase in the link failure. The higher delivery ratio achieved by EAODV is due to the selection of route involving the nodes with minimum 
energy level along with shortest route for transmission of data from source to destination node.

It is depicted through the Figure 4 that EAODV provides higher delivery ratio of approximately $5 \%$ than that of AODV for different coverage area with consideration of 100 nodes. The improvement in delivery ratio is due to the fact that EAODV selects neighbor node having minimum energy level as well as shortest path. The reduced delivery ratio for increased coverage area is due to more random nature of nodes which increases packet loss.

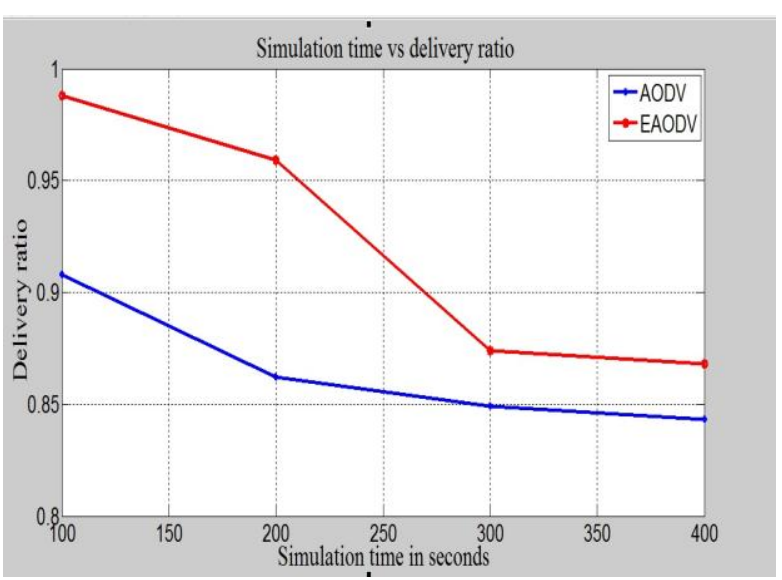

Figure 3. Delivery Ratio with respect to simulation time

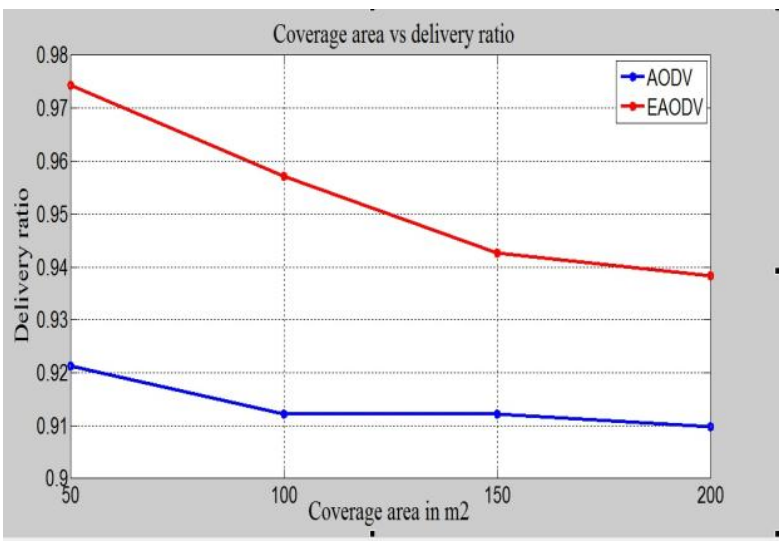

Figure 4. Delivery Ratio for different coverage area $\left(\mathbf{m}^{2}\right)$

\subsection{Delay Analysis}

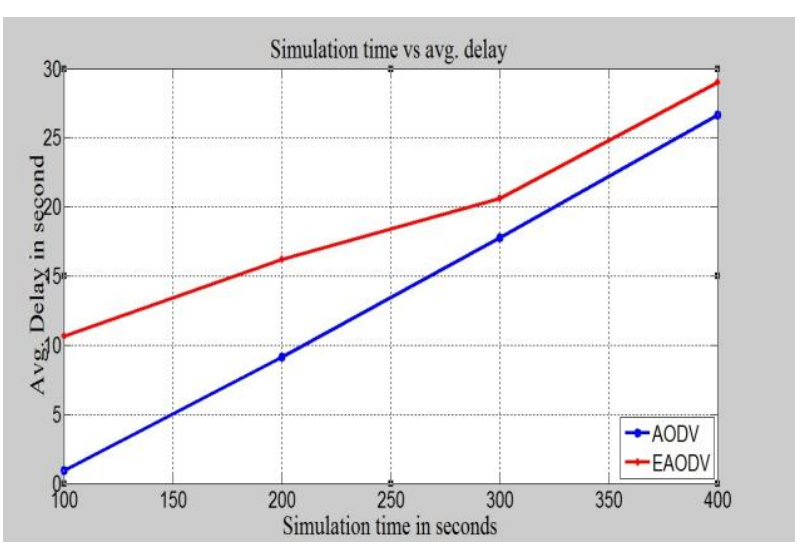

Figure 5. Average delay with respect to simulation time
It is verified through simulation result shown in Figure 5 that delay of EAODV protocol is higher than that of AODV protocol. The increment in delay is due to the fact that EAODV selects intermediate nodes based upon their energy levels in addition to the shortest route which will increase the path length.

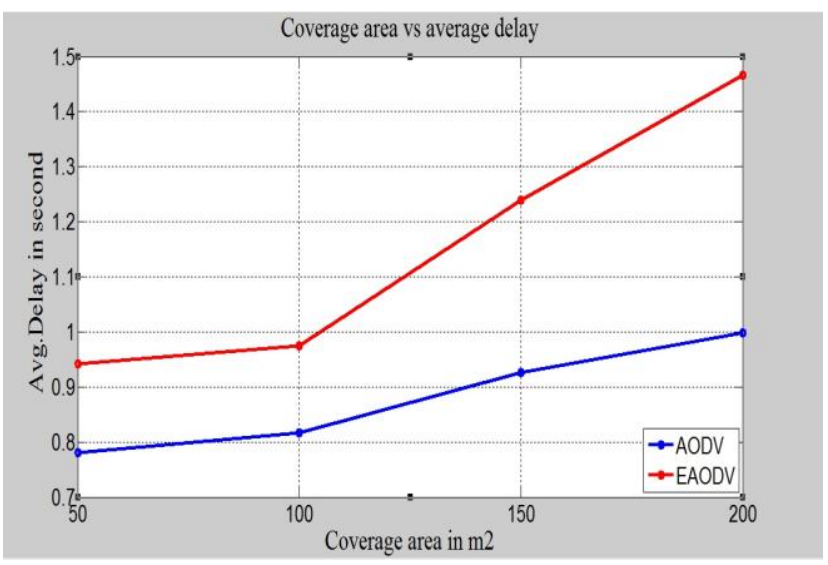

\section{Figure 6. Average delay for different coverage area $\left(\mathbf{m}^{2}\right)$}

The end to end delay of EAODV is higher than the AODV demonstrated in Figure 6. The higher delay attained by EAODV for larger coverage area is due to the more number of hops taken by path involving the nodes based upon their energy levels in addition to the shortest route to transfer the packets from source to target node.

\section{CONCLUSION}

Wireless sensor networks have emerged as an important new area in wireless technology. The key challenge in sensor networks is to maximize the lifetime of sensor nodes due to the fact that it is not feasible to replace the batteries of thousands of sensor nodes. Therefore, computational operations of nodes and communication protocols must be made as energy efficient as possible. Hence, energy efficient routing protocols are required for sensor networks. EAODV protocol is developed for IEEE 8012.15.4 enabled WSN by using ns-2.35. The performance parameters such as delivery ratio and delay of EAODV are determined and also compared with AODV protocol by varying the simulation time from 100 s to 400 s considering 100 nodes for different coverage areas of $50 \times 50 \mathrm{~m}^{2}$ to $200 \times 200 \mathrm{~m}^{2}$. The results show that an improvement of approximately 5\% in delivery ratio is achieved by using the EAODV protocol than the standard AODV. This is mainly due to the successful transmission of packets from source to destination by considering path having minimum energy level nodes and shortest route. However, the delay of EAODV protocol is higher than that of AODV.

\section{REFERENCES}

[1] Ian F. Akyildiz, Su,W, Sankara subramaniam ,Y, and Cayirci. E. 2002, "A survey on sensor networks" IEEE Communications Magazine, vol. 40, no. 8, pp.102-114, August.

[2] Amato, G., Caruso, A., Chessa, S. 2009, "Application-driven, energy-efficient communication 
in wireless sensor networks". Computer Communications, vol. 32, no.5,pp. 896 - 906, March.

[3] Anitha, P., Dr.Chandrasekar, C. 2011, "Energy Aware Routing Protocol for Zigbee Networks" Journal of Computer Applications, vol. 4, no. 3, pp.18-21, October.

[4] Chao, C-M., Sheu,J-P., and Hu, C-T.2003, "Energy Conserving Grid Routing Protocol in Mobile Ad-Hoc Networks", Proceedings of IEEE International Conference on Parallel Processing, pp 265-272, October.

[5] Perkins, C. and Royer, E. 1999, "Ad hoc on demand distance vector (AODV) routing," Proceedings. of IEEE Workshop on Mobile Computing Systems and Applications ,New Orleans, LA, pp. 99-100, Febuary.

[6] Gowrishankar, S., Sarkar, S.K.and Basavaraju, T.G.2009, "Performance analysis of AODV, AODVUU, AOMDV and RAODV over IEEE 802.15.4 in wireless sensor networks", Proceeding of 2nd IEEE International Conference on Computer Science and Information Technology, Beijing pp. 5963, 8-11. August.

[7] Liu HI., and Li,Y.Y. 2003, "DL-GRID: A QoS Routing Protocol for Ad-Hoc Networks", Proceedings of 57th IEEE Conference. on Vehicular Technology, vol. 3, pp. 1744-1748, April

[8] Asar Ali and Zeeshan Akbar.2009. "Evaluation of AODV and DSR Routing Protocols of Wireless Sensor Networks for Monitoring Applications, Thesis Report, Department of Electrical engineering with Telecommunication, Blekinge Institute of Technology, October.

[9] Akkaya,K. and Younis,M.2005, "A Survey of Routing Protocols in Wireless Sensor Networks",
Elsevier Ad Hoc Network Journal, vol.3, no.3, pp.325-349, November .

[10]Geetha Jayakumar, Gopinath Ganapathy. 2007, "Performance Comparison of Mobile Ad-hoc Network Routing Protocol", International Journal of Computer Science and Network Security, vol. 7, no.11, pp. 77-84, November.

[11] Andrew Wheeler. 2007, "Commercial Applications of Wireless Sensor Networks Using Zigbee", IEEE Communication Magazine, vol. 45, no.4, pp. 70-77, April.

[12] Network Simulator ns-2 www.isi.edu/nsnam/ns/

\section{AUTHOR'S PROFILE}

P. Samundiswary received the B.Tech. degree (1997), M.Tech degree (2003) and Ph.D. (2011) in the department of Electronics and Communication Engineering from Pondicherry Engineering College affiliated to Pondicherry University, Pondicherry, India. She is having 14 Years of teaching experience. She is currently working as Assistant Professor in the Dept. of Electronics Engineering, School of Engineering and Technology, Pondicherry University, Pondicherry, India. Her research interests include Wireless Communication and Wireless Networks.

Hemant Bhardwaj obtained his B.Tech. degree (2010) in Electronics and Communication Engineering from Shri Rawatpura Institute of Technology and Science, affiliated to RGTU Bhopal. Currently, he is studying M.Tech in the Dept. of Electronics Engineering, School of Engineering and Technology, Pondicherry University, Pondicherry, India. 